\title{
Osmotrophic glucose and leucine assimilation and its impact on EPA and DHA content in algae
}

\author{
Elina T Peltomaa ${ }^{\text {Corresp., } 1}$, Sami J Taipale ${ }^{2}$ \\ 1 Faculty of Biological and Environmental Sciences, Lammi Biological Station, University of Helsinki, Lammi, Finland \\ 2 Department of Biological and Environmental Science, University of Jyväskylä, Jyväskylä, Finland \\ Corresponding Author: Elina T Peltomaa \\ Email address: elina.peltomaa@helsinki.fi
}

The uptake of dissolved organic compounds, i.e. osmotrophy, has been shown to be an efficient nutritional strategy for algae. However, this mode of nutrition may affect the biochemical composition, e.g. the fatty acid contents, of algal cells. This study focused on the osmotrophic assimilation of glucose and leucine by selected seven algal strains belonging to chlorophytes, chrysophytes, cryptophytes, dinoflagellates and euglenoids. Our laboratory experiments with stable isotope labeling showed that osmotrophy occurred in four of the selected seven strains. However, only three of these produced long chain omega-3 fatty acids eicosapentaenoic acid (EPA; 20:5w3) and docosahexaenoic acid (DHA; 22:6w3). High glucose content $\left(5 \mathrm{mg} \mathrm{L}^{-1}\right)$ affected negatively on the total fatty acids of Mallomonas kalinae and the total omega-3 fatty acids of Cryptomonas sp. Further, glucose assimilation explained 35\% (negative effect) and leucine assimilation 48\% (positive effect) of the variation of EPA, DHA and the fatty acids related to their synthesis in Cryptomonas $\mathrm{sp}$. Moderate glucose concentration $\left(2 \mathrm{mg} \mathrm{L}^{-1}\right)$ was found to enhance the growth of Cryptomonas ozolinii, whereas low leucine $\left(20 \mu \mathrm{g} \mathrm{L}^{-1}\right)$ enhanced the growth of Mallomonas kalinae. However, no systematic effect of osmotrophy on growth rates was detected. Our study shows that osmotrophic assimilation of algae is species and compound specific, and that the effects of the assimilated compounds on algal metabolism also varies depending on the species. 
4 Osmotrophic glucose and leucine assimilation and its

5 impact on EPA and DHA content in algae

6

7

8 Elina Talvikki Peltomaa ${ }^{1}$ and Sami Johan Taipale ${ }^{2}$

$9{ }^{1}$ Faculty of Biological and Environmental Sciences, Lammi Biological Station, University of

10 Helsinki, Lammi, Finland

11 2Department of Biological and Environmental Science, University of Jyväskylä, Jyväskylä,

12 Finland

13

14 Corresponding Author:

15 Elina Peltomaa

16 Lammi Biological Station, Pääjärventie 320, 16900 Lammi, Finland

17 Email address: elina.peltomaa@helsinki.fi 


\section{Abstract}

20 The uptake of dissolved organic compounds, i.e. osmotrophy, has been shown to be an efficient

21 nutritional strategy for algae. However, this mode of nutrition may affect the biochemical

22 composition, e.g. the fatty acid contents, of algal cells. This study focused on the osmotrophic

23 assimilation of glucose and leucine by selected seven algal strains belonging to chlorophytes,

24 chrysophytes, cryptophytes, dinoflagellates and euglenoids. Our laboratory experiments with

25 stable isotope labeling showed that osmotrophy occurred in four of the selected seven strains.

26 However, only three of these produced long chain omega-3 fatty acids eicosapentaenoic acid

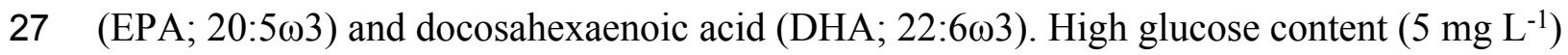

28 affected negatively on the total fatty acids of Mallomonas kalinae and the total omega-3 fatty

29 acids of Cryptomonas sp. Further, glucose assimilation explained 35\% (negative effect) and

30 leucine assimilation $48 \%$ (positive effect) of the variation of EPA, DHA and the fatty acids

31 related to their synthesis in Cryptomonas sp. Moderate glucose concentration $\left(2 \mathrm{mg} \mathrm{L}^{-1}\right)$ was

32 found to enhance the growth of Cryptomonas ozolinii, whereas low leucine $\left(20 \mu \mathrm{g} \mathrm{L}^{-1}\right)$ enhanced

33 the growth of Mallomonas kalinae. However, no systematic effect of osmotrophy on growth

34 rates was detected. Our study shows that osmotrophic assimilation of algae is species and

35 compound specific, and that the effects of the assimilated compounds on algal metabolism also

36 varies depending on the species. 


\section{Introduction}

38 Mixotrophy, i.e. the ability of an organism to combine autotrophy and heterotrophy and thus get

39 sustenance simultaneously from inorganic and organic sources, is gaining increasing attention in studies of aquatic as well as terrestrial ecosystems. In aquatic habitats, mixotrophy is common in unicellular organisms such as algae, cyanobacteria and protists (Flynn et al. 2013; Schmidt et al. 2013). The heterotrophic nutrition in mixotrophy is via phagotrophy (particle or cell uptake) or osmotrophy (uptake of dissolved organic compounds), both of which may occur in tandem with photosynthesis or during dark periods, e.g. nights.

The detection of mixotrophic behavior can be challenging both in laboratory and field conditions, and thus, for example, radioactive isotope labelling has been applied to study the osmotrophic nutrient uptake (Kamjunke \& Tittel 2008; Tittel et al. 2009; Beamud et al. 2014). These studies have shown that many algae have the ability to assimilate carbohydrates (e.g. glucose), amino acids (e.g. glutamine, leucine, thymidine, aspartic acid) and other organic compounds (e.g. acetic acid, coumaric acid, glycerol), which they use as carbon and nitrogen sources, and which are commonly released by the algae themselves or by bacteria (Hellebust 1965; Kamjunke\& Tittel 2008; Tittel et al. 2009; Beamud et al. 2014; Dąbrowska et al. 2014).

Osmotrophy has been shown to be an efficient nutrition strategy for algae in nature: osmotrophic assimilation of amino acids prevent nitrogen limitation, which favors biomass growth in oligotrophic lakes (Kamjunke \& Tittel 2008). Similarly, osmotrophic uptake of fulvic acids enhances biomass growth and boost bloom forming in humic lakes (Rengefors et al. 2008).

Osmotrophic nutrition may affect the biochemical composition of algal cells. Biosynthesis of various molecules is determined by phylogeny-based traits and there is a significantly different composition of, for example, fatty acids (FAs) in different algal taxa (Kohli et al. 2016). It is reported that growth conditions account for relatively low variation in algal FAs compared to phylogeny (Galloway \& Winder 2015), however, studies with Ochromonas sp. (Boechat et al. 2007) showed decreased polyunsaturated fatty acid (PUFA) concentration by feeding mode. Thus, even though the FA profiles and the quality of synthetized FAs may not change, the quantity of different FAs might be affected by the growth mode. For example, nitrogen limitation favors FA synthesis and lipid accumulation in algal cells, and thus if algae can assimilate leucine 
68 and use it as their nitrogen source, they should not start to accumulate lipids but carry on cell

69 division as long as the other essential nutrients are available. In turn, osmotrophically assimilated

70 glucose is channeled directly into lipid synthesis, i.e. to palmitic acid (16:0), which results in

71 building up of triacylglycerols and e.g. long chain polyunsaturated fatty acids (LC-PUFAs;

72 Ratledge 2004). Some LC-PUFAs belong to omega-3 FAs (e.g. eicosapentaenoic acid [EPA;

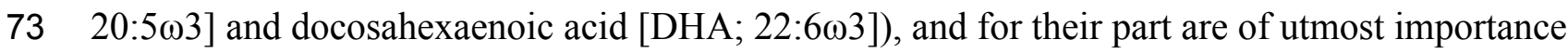

74 for the growth and reproduction of consumers in aquatic food webs (Peltomaa et al. 2017;

75 Taipale et al. 2018). Since algae are practically the only primary source of EPA and DHA in 76 aquatic food webs (Colombo et al. 2017), osmotrophic nutrient uptake may affect the whole food 77 web by influencing the availability of these nutritionally essential compounds, and thus the 78 growth and reproduction of upper trophic levels (Jonasdottir 1994; Brett et al. 2006; Peltomaa et 79 al. 2017; Taipale et al. 2018).

80

81 In this study we focused on the osmotrophic uptake of glucose and leucine by selected seven 82 algal strains belonging to chlorophytes, chrysophytes, cryptophytes, dinoflagellates and 83 euglenoids. We conducted short-term stabile isotope labelling experiments with these algae to

\section{Materials \& Methods} their total FA content. determine if they are able to assimilate glucose and/or leucine. Since we were especially interested in the effects of osmotrophy on EPA and DHA production, we analyzed the fatty acids of these strains. For studying the impact of osmotrophy on fatty acid synthesis, we selected the EPA and DHA synthesizing osmotrophic strains and cultured them with glucose, leucine and mix of these two in a long-term experiment for 14 days, i.e. until the cultures reached the stationary or late exponential phase, during which the LC-PUFAs are mobilized from the membranes into storage lipids (Roessler 1990; Boelen et al. 2017). We hypothesized that (1) all of the strains are osmotrophic, i.e. assimilate glucose and leucine, (2) osmotrophy has positive effect on their growth, and that (3) the osmotrophic uptake of glucose increases the EPA and DHA concentrations in algae capable of synthesizing these fatty acids, whereas (4) the uptake of leucine does not affect specifically their EPA and DHA concentrations, but may actually lower

\section{The algal strains and growth conditions}


99 The studied algal strains were from freshwater origin, and included chlorophytes

100 Chlamydomonas reinhardtii (from the collection of the University of Washington, UWCC) and

101 Selenastum sp. (SCCAP K-1877), chrysophyte Mallomonas kalinae (SCCAP K-1759),

102 cryptophytes Cryptomonas sp. (CPCC 336) and C. ozolinii (UTEX LB 2782), dinoflagellate

103 Peridinium sp. (author's collection, isolated from Lake Valkea-Kotinen, Finland, $61.14^{\circ} \mathrm{N}$,

$10425.04^{\circ} \mathrm{E}$ in 2015) and euglenoid Euglena gracilis (CCAP 1224/5Z). The stock cultures of the

105 strains were grown autotrophically in AF6 medium (E. gracilis; Watanabe 2000) or MWC

106 medium (all the other strains; Guillard \& Lorenzen 1972) at $20{ }^{\circ} \mathrm{C}$ under light:dark cycle of 16:8

$107 \mathrm{~h}$ with light intensity of $70-100 \mu \mathrm{mol} \mathrm{m} \mathrm{m}^{-2} \mathrm{~s}^{-1}$. The cultures were not axenic, but the initial

108 numbers of bacteria were low due to the growth media consisting of inorganic nutrients. The

109 bacterial numbers were not determined, but bacterial FA biomarkers were included in the FA

110 analysis (see below). The algal cultures were grown to late exponential phase before they were

111 used in the experiments.

112

113 Short-term stable isotope labelling experiments

114 For the short-term stable isotope experiment, the autotrophically grown seven algal strains were

115 grown to stationary phase, collected with centrifugation into pellets $(200 \mathrm{~mL}, 5 \mathrm{~min}, 2000 \mathrm{rpm}$,

116 which was pre-examined as safe for the fragile flagellates), and further resuspended into $50 \mathrm{~mL}$

117 of fresh AF6 (E. gracilis) or MWC media (all the other strains) enriched with glucose $5 \mathrm{mg} \mathrm{L}^{-1}$

118 (containing $4.9 \mathrm{mg} \mathrm{L}^{-1}$ non-labeled D-(+)-Glucose [Sigma-Aldrich Co., St Louis, MO, USA] and

$1190.1 \mathrm{mg} \mathrm{L}^{-1}{ }^{13} \mathrm{C}$-labeled D-Glucose [Sigma-Aldrich Co.]) or with leucine $400 \mu \mathrm{g} \mathrm{L}^{-1}$ (containing

$120392 \mu \mathrm{g}$ non-labeled L-Leucine [Sigma-Aldrich Co.] and $8 \mu \mathrm{g}{ }^{15} \mathrm{~N}$-labeled L-Leucine [Sigma-

121 Aldrich Co.]) or with both. Three independent replicates were used for each algae and treatment,

122 and non-labeled autotrophic controls were run in parallel. The incubation took place at $20^{\circ} \mathrm{C}$

123 under a constant light intensity of $70-100 \mu \mathrm{mol} \mathrm{m}^{-2} \mathrm{~s}^{-1}$, i.e. the possible dark-time heterotrophic

124 assimilation of glucose and leucine was excluded from this short-term experiment. The

125 incubation time was only 30 minutes to preventing respiration loss of the labels, but it was still

126 long enough to acquiring detectable changes in cellular $\delta^{13} \mathrm{C}$ and $\delta^{15} \mathrm{~N}$ concentrations. After the

127 incubation, the samples were centrifuged (2000 rpm, $5 \mathrm{~min})$, the supernatants were discarded,

128 and the pellets were flushed by diluting them into $30 \mathrm{~mL}$ of fresh AF6 (E. gracilis) or MWC

129 media (all the other strains) and centrifuging them again. After discarding the supernatants, the 
130 pellets were frozen in $-80{ }^{\circ} \mathrm{C}$, and freeze-dried within two days. The $\delta^{13} \mathrm{C}$ and $\delta^{15} \mathrm{~N}$ as well as 131 fatty acid profiles were analyzed from these samples.

132

133 The $\delta^{13} C$ and $\delta^{15} N$ analyses

134 For the $\delta^{13} \mathrm{C}$ and $\delta^{15} \mathrm{~N}$ analyses, approximately $2 \mathrm{mg}$ of the freeze-dried algal biomass was 135 weighed into tin capsules. The analyses were carried out on a Carlo-Erba Flash 1112 series 136 Element Analyzer connected to a Thermo Finnigan Delta Plus Advantage IRMS (Thermo Fisher 137 Scientific, USA). Four replicates were run from each sample. The samples were compared to the 138 NBS-22 standard using birch leaf powder as a laboratory-working standard. The precision of the $139 \delta^{13} \mathrm{C}$ and the $\delta^{15} \mathrm{~N}$ analyses were $0.2 \%$ and $0.3 \%$, respectively, for all samples.

141 Fatty acid analysis

142 Two replicates of each freeze-dried sample were weighed (1-2 mg/sample) into tin capsules and

143 the lipids were extracted using chloroform:methanol (2:1) NaCl -method (Parrish 1999). Toluene 144 and sulfuric acid were used for the transesterification of fatty acid methyl esters (FAMEs) at 90 $145{ }^{\circ} \mathrm{C}$ for $1 \mathrm{~h}$. The FAMEs were analyzed with a gas chromatograph (Shimadzu Ultra, Japan) 146 equipped with a mass detector (GC-MS; Shimadzu Ultra, Kyoto, Japan) and using helium as a 147 carrier gas and an Agilent ${ }^{\circledR}$ (Santa Clara, CA, USA) DB-23 column $(30 \mathrm{~m} \times 0.25 \mathrm{~mm} \times 0.15$ $148 \mu \mathrm{m})$. Fatty acid concentrations were calculated using calibration curves based on known standard 149 solutions of a FAME standard mixture (GLC standard mixture 566c, Nu-ChekPrep, Elysian, 150 MN, USA) (see Taipale et al. 2016 for further details). The 16:0, alpha-linolenic acid (ALA;

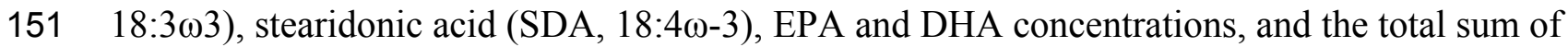
152 monounsaturated fatty acids with 16 carbons (16 MUFAs) and 18 carbons (18 MUFAs) were in 153 the focus of this study and thus reported here. The fatty acid biomarkers for bacteria (i-14:0, i154 15:0, a-15:0, i-16:0, i-17:0 and a-17:0; Brennan 1989; Taipale et al. 2015) were also detected in 155 order to ensure that the numbers of bacteria were low, i.e. the glucose and leucine were 156 assimilated by the algae, not by bacteria.

157

158 The long-term osmotrophy experiments

159 The long-term experiments were done only for those three strains that were detected to be 160 osmotrophic (i.e. assimilated either glucose or leucine or both in the short-term experiment) and, 
161 based on the results from the short-term study, were detected to synthetize either EPA or DHA or 162 both. These strains were: M. kalinae, Cryptomonas sp. and C. ozolinii. The long-term 163 experiments were run in independent triplicates, and using three different glucose $(0.5,2$ and 5 $\left.164 \mathrm{mg} \mathrm{L}^{-1}\right)$ and leucine $\left(20,100\right.$ and $\left.400 \mu \mathrm{g} \mathrm{L}^{-1}\right)$ concentrations selected based on literature 165 (Kamjunke et al. 2008, Kamjunke \& Tittel 2008). There were no mixed treatments of glucose 166 and leucine, but autotrophic controls were run in parallel. The algal cells were collected into 167 pellets from the stock cultures similarly to short-term experiments before transferring them into 168 the experimental flasks of $250 \mathrm{~mL}$. The strains were grown for 15-16 days in similar conditions 169 as the algal stock cultures and the growth was followed through microscopic counts every third 170 day using Sedgewick Rafter - counting cells and preservation with acid Lugol's solution (Willén 171 1962). The specific growth rates $\left(\mu ; \mathrm{d}^{-1}\right)$ for all strains were calculated using the equation 1 . The 172 cells were grown into the stationary or late exponential phase (Fig. S1), harvested during the 173 light-period of the light:dark-cycle, and pelleted, frozen $\left(-80^{\circ} \mathrm{C}\right)$ and freeze-dried. The fatty acid 174 profiles were analyzed similarly to the short-term samples (see above), but only from two 175 replicates of each treatment and from one control.

176

$$
\mu=\ln \left(\operatorname{cells}_{\mathrm{x}} / \mathrm{cells}_{0}\right) /\left(\mathrm{T}_{\mathrm{x}}-\mathrm{T}_{0}\right)
$$

178

179

180

181

182

183

184

185

186

187

188

189

190

191

where:

$\mu$ is the specific growth rate

cells $\mathrm{T}_{0}$ is the cell number at time $0\left(\mathrm{~T}_{0}\right)$

cells $\mathrm{T}_{\mathrm{x}}$ is the cell number at time $\mathrm{x}\left(\mathrm{T}_{\mathrm{x}}\right)$

\section{Statistical analyses}

The results of the short-term isotope labelling experiments were statistically tested with t-test by comparing the non-labeled autotrophic control samples with the labeled samples. The effects of osmotrophy on growth and FA contents were in the long-term experiment tested with the analysis of variance (ANOVA) and Tukey's honestly significant difference (HSD) post hoc test. Levene's test was used for testing the homogeneity of variances. Principal component analysis (PCA), permutational multivariate analysis of variance (PERMANOVA) and similarity percentages (SIMPER) were used for a more detailed study of the similarity of the FA profiles 
192 between the treatments in the long-term experiment. In PCA the 16:0, alpha-linolenic acid

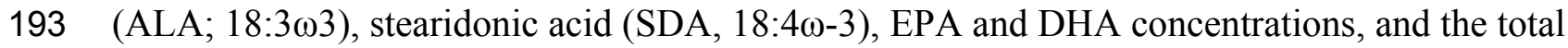
194 sum of monounsaturated fatty acids with 16 carbons (16 MUFAs) were included in the analysis. 195 In PERMANOVA and SIMPER the analysis included the above mentioned FAs and also 196 MUFAs with 18 carbons (18 MUFAs). All glucose treatments and all leucine treatments were 197 pooled for the analysis in PERMANOVA and SIMPER. PERMANOVA was run with 198 unrestricted permutation of raw data and type III sums of squares. Monte Carlo adjustment was 199 used in PERMANOVA due to low numbers of replicates. In the statistical testing, p-values < 2000.05 were considered as significant. ANOVA and Tukey's and Levene's tests were conducted 201 with IBM SPSS Statistics for Windows, Version 22.0 (IBM Corp., Armonk, NY, USA). PCA, 202 PERMANOVA and SIMPER were done using Primer 7 (version 7.0.13, Quest Research 203 Limited, Auckland, New Zealand).

204

\section{Results}

206 The osmotrophic glucose and leucine uptake

207 The studied strains showed different responses to glucose and leucine additions in the short-term 208 experiment (Fig. 1, Table S1). The chlorophyte C. reinhardtii, the dinoflagellate Peridinium sp. 209 and the euglenoid E. gracilis did not show glucose or leucine assimilation at all. Whereas, the 210 chlorophyte Selenastrum sp. assimilated both compounds (glucose t-test $\mathrm{p}<0.001$, leucine t-test $211 \mathrm{p}=0.04$ ), as did also the cryptophytes Cryptomonas $\mathrm{sp}$. (glucose $\mathrm{t}$-test $\mathrm{p}<0.01$, leucine $\mathrm{t}$-test $\mathrm{p}=$ 2120.02 ) and $C$. ozolinii (glucose t-test $\mathrm{p}<0.01$, leucine t-test $\mathrm{p}<0.001$ ). The chrysophyte $M$.

213 kalinae did not assimilate glucose, but assimilated leucine (t-test $\mathrm{p}<0.01$ ).

214

215 Fatty acid profiling of the short-term experiment

216 The fatty acid profiling of the short-term experiments showed that the strains capable of EPA 217 and/or DHA synthesis were M. kalinae (average EPA $0.3 \%$ of all FAs, sd 0.0; average DHA 3.2 $218 \%$ of all FAs, sd 0.1), Cryptomonas sp. (EPA $17.6 \%$, sd 0.0; DHA $2.3 \%$, sd 0.0), C. ozolinii 219 (EPA $13.9 \%$, sd 1.3; DHA $2.1 \%$, sd 0.2), Peridinium sp. (EPA 13.4, sd 0.0; DHA 25.1, sd 0.6) 220 and E. gracilis (EPA $14.3 \%$, sd 0.8; DHA 8.4\%, sd 0.2). However, because only M. kalinae, 221 Cryptomonas sp. and C. ozolinii were showing osmotrophic uptake of glucose and/or leucine, 
222 these three strains were selected for the long-term experiment. Fatty acid biomarkers for bacteria 223 (i-14:0, i-15:0, a-15:0, i-16:0, i-17:0 and a-17:0) were not found in the analysis.

224

225

The effect of osmotrophy on growth, total FAs and EPA and DHA production

226 In general, C. ozolinii had higher specific growth rates than the two other studied strains in the 227 long-term experiment. The highest growth rate in C. ozolinii $\left(\mu=0.88 \mathrm{~d}^{-1}\right.$; ANOVA p $\left.<0.01\right)$ 228 was detected with moderate glucose concentration of $2 \mathrm{mg} \mathrm{L}^{-1}$, and in M. kalinae $\left(\mu=0.47 \mathrm{~d}^{-1}\right.$, 229 ANOVA $\mathrm{p}<0.01$ ) with low leucine concentration of $20 \mu \mathrm{g} \mathrm{L}-1$, but otherwise there were no 230 signs that the osmotrophic nutrition would have had increased or decreased the growth rates of 231 the studied three strains (Table 1).

233 The highest total FA concentration (i.e. $88.8 \mu \mathrm{g}$ FA in mg DW) was found in the autotrophic $M$.

234 kalinae, and the total fatty acids of M. kalinae were also detected to vary according to the 235 treatment that was lowest $(33.8 \mu \mathrm{g}$ FA in $\mathrm{mg} \mathrm{DW})$ in the $5 \mathrm{mg} \mathrm{L}^{-1}$ glucose treatment (Table 2). 236 However, it could not be firmly stated that either glucose or leucine addition would have had 237 certain effects on the total FA content in M. kalinae. There were no treatment-based variation in 238 the total FAs of the two cryptophytes either, but there was species specific variation: the total FA 239 concentrations in Cryptomonas sp. (52.8-73.6 $\mu \mathrm{g}$ FA in mg DW) were substantially higher in all 240 treatments than in C. ozolinii (range 32.9-45.1 $\mu \mathrm{g}$ FA in mg DW; Table 2). Fatty acid biomarkers 241 for bacteria (i-14:0, i-15:0, a-15:0, i-16:0, i-17:0 and a-17:0) were not found in the FA analysis.

243 The proportion of omega-3 FAs (i.e. ALA, SDA, EPA and DHA) out of total FAs varied 244 between the strains being lowest in M. kalinae (range 21.3-40.3\%), and was substantially higher 245 in Cryptomonas sp. (range 76.8-89.9\%) and in C. ozolinii (69.9-94.8\%; Fig. 2). The PCA plot of 246 the omega-3 FAs clustered the strains into their own groups in spite of the growth conditions 247 (Fig. 3) indicating strong genetic control of FA profiles and synthesis. When EPA and DHA 248 were studied more in detail, no clear evidence of the effects of osmotrophy on the contents of 249 these FAs were found with ANOVA: in M. kalinae EPA and its precursor ALA varied between 250 the treatments, in Cryptomonas sp. variations were found in 16:0, ALA and EPA, and in C. 251 ozolinii in EPA and DHA, but either glucose or leucine could not be stated to have specific effect 252 on these omega-3 FAs (Tables 2, S2). However, when the 16:0, ALA, SDA, EPA, DHA, 16 
253 MUFA and 18 MUFA concentrations were studied with PERMANOVA, the glucose

254 assimilation were found to explain 35\% (PERMANOVA, $\left.\mathrm{F}_{(3,6)}=2.74, \mathrm{p}=0.025\right)$ and the leucine 255 assimilation $48 \%$ (PERMANOVA, $\mathrm{F}_{(3,6)}=3.78, \mathrm{p}=0.021$ ) of the variation in these FAs in 256 Cryptomonas sp. (Table 3). Statistically significant results were not found with PERMANOVA 257 for M. kalinae or C. ozolinii (Table 3). These observations are in line with the results of the PCA 258 (Fig. 3), indicating that Cryptomonas sp. differ from M. kalinae, but also from C. ozolinii. 259

\section{Discussion}

261 In this study, we focused on the osmotrophic nutrition and omega-3 FA production of seven algal 262 strains representing chlorophytes, chrysophytes, cryptophytes, dinoflagellates and euglenoids. 263 We expected that all of the studied strains would assimilate glucose and leucine (Hypothesis 1), 264 but this was not the case. The chlorophyte C. reinhardtii, the dinoflagellate Peridinium sp. and 265 the euglenoid E. gracilis did not assimilate either glucose or leucine during the 30 minutes 266 incubation period of our short-time experiment. Furthermore, the chrysophyte M. kalinae 267 assimilated only leucine. The uptake velocities of different algae may vary for different compounds (North and Stephens 1972) and depending on the growth mode (Wheeler et al. 1974), and thus it is possible that even though our cultures were on stationary phase and assumingly depleted by nutrients, our 30 min incubation time was not sufficient enough for assimilation for some of the algae used in this study. We did the incubations in light, which also

272 could have affected the results, since in some cases algae have shown higher osmotrophic 273 assimilation in dark than in light for glucose (Beamud et al. 2014) and leucine (Ruiz-González et 274 al. 2012). However, many algal species are reported to enhance their osmotrophic uptake in light 275 (Tittel et al. 2009; Beamud et al. 2014). Additionally, our experiments were done in nutrient-rich 276 AF6 or MWC medium, but inorganic nutrient limitation could have triggered rapid osmotrophic 277 uptake (Kamjunke \& Tittel 2008). However, it has also been shown by Beamud et al. (2014) that 278 osmotrophic feeding mode is not triggered only by nutrient deficiency: in their study the 279 chlorophytes Keratococcus rhaphidioides and Watanabea sp. assimilated leucine, thymidine, 280 aspartic acid and acetate also under high levels of inorganic nitrogen and phosphorus, and not only during nutrient limitation. Altogether, our study and the previous observations show that osmotrophic assimilation of algae is both species and compound specific, and that generalizations on the occurrence of osmotrophy within certain taxa cannot be done. 
285 For studying the effects on osmotrophy on algal fatty acids, especially the LC-PUFAs, the FA 286 profiles of the strains were screened in the short-term study. It is already known that most EPA

287 288 289

290

291

292

293

294

295

296

297

298

299

300

301

302

303

304

305

306

307

308

309

310

311

312

313

314 and DHA producing algae belong to the kingdom Chromista, i.e. to cryptophytes, haptophytes and heterokonts (Cavalier-Smith 2010; Mühlroth et al. 2013). This was the case also with our algae: EPA and DHA was found in all strains excluding the chlorophytes $C$. reinhardtii and Selenastrum sp. However, since we specifically focused on the effects of osmotrophic nutrition on EPA and DHA production, only M. kalinae and the two cryptophyte strains showing osmotrophic assimilation were studied in our long-term experiment. In this experiment, we expected that (Hypothesis 2) the growth rates would have been enhanced by the osmotrophic growth mode, as has earlier been reported for the raphidophyte Gonyostomum semen (Rengefors et al. 2008) and for the chlorophytes K. rhaphidioides and Watanabea sp. (Beamud et al. 2014). This however was not the case, and excluding some statistically significant differences in the growth rates of $M$. kalinae and $C$. ozolinii, the growth rates could not be directly related to glucose or leucine assimilation. We cannot fully explain the reason behind these two observations on higher growth rates, but are aware that for example mixotrophic phagotrophy on bacteria may increase algal growth (Yoo et al. 2017). We did not observe high amounts of bacteria in the samples during the algal cell counts or detect bacterial FA biomarkers in the FA analysis. However, we did not calculate the bacterial numbers nor study the possible assimilation of bacteria by the algal strains, and thus cannot explicitly state that phagotrophic mixotrophy did not occur during the long-term experiment.

Because glucose is channeled directly to palmitic acid (16:0) and further into lipid synthesis (Ratledge 2004), and the cellular neutral lipid content should be at highest during the light period of the light:dark cycle (Roessler 1990), and because the LC-PUFA content should be at highest during the stationary growth phase (Roessler 1990; Boelen et al. 2017), we expected (Hypothesis 3 ) that the osmotrophic uptake of glucose increases the FA content in algae. However, we did not find any specific effect of glucose on the amount of total FAs or EPA or DHA. Our PERMANOVA analysis for EPA and DHA, and the FAs related to the synthesis of these LCPUFAs (16:0, ALA, SDA, 16 MUFA, 18 MUFA), showed that the glucose assimilation explained (35\%) the concentrations of these FAs in Cryptomonas sp., but the effect was rather 
315 negative than positive (Fig. 2). It has been shown earlier that too high glucose concentration may 316 inhibit growth and lipid synthesis and that the optimal glucose content is species specific (Liang 317 et al. 2009; Wan et al. 2011). This effect was seen besides in the omega-3 in Cryptomonas sp. 318 also in the total FA content in M. kalinae, which had lowest total FAs in the highest glucose 319 treatment $\left(5 \mathrm{mg} \mathrm{L}^{-1}\right)$.

320

321 In contrast to glucose addition, we expected that (Hypothesis 4) the leucine addition would not 322 affect the EPA and DHA content of algae, but could boost their growth and thus simultaneously 323 actually reduce the amount of stored FAs. However, the growth rates were not affected by 324 leucine, and reduction in the total FAs compared to control was found only in M. kalinae in 325 leucine $100 \mu \mathrm{g} \mathrm{L}^{-1}$ treatment. For our surprise, in PERMANOVA, leucine assimilation explained 326 $48 \%$ of the variation in the content of 16:0, ALA, SDA, EPA, DHA 16 MUFA and 18 MUFA of Cryptomonas sp., and - unlike expected - the effect of leucine was positive. Again, these results show that biochemical synthesis in algae is species specific, and that generalizations cannot be 329 made.

330

We selected the glucose and leucine concentrations based on literature (Kamjunke \& Tittel 2008; 332 Kamjunke et al. 2008), and they are in line with the dissolved organic carbon (DOC) contents of 333 natural lakes; the DOC content in the clearwater lakes in Finland vary between 7-9 $\mathrm{mg} \mathrm{C} \mathrm{L}^{-1}$

334 (Ojala et al. 2011; Brek-Laitinen et al. 2012), whereas in humic lakes the DOC values can be 335 even higher (10 to $45 \mathrm{mg} \mathrm{C} \mathrm{L}^{-1}$; Taipale et al. 2008; Ojala et al. 2011). However, in nature the 336 DOC consists of both recalcitrant compounds from mainly terrestrial origin and labile compounds released by algae and bacteria. Further, the labile compounds constitute of different carbohydrates, organic acids, dissolved and free amino acids, ketones and aldehydes with variable concentrations (Hellebust 1965; Norrman et al. 1995; Peltomaa \& Ojala 2010;

340 Dąbrowska et al. 2014), which makes the detection of osmotropic assimilation as well as the 341 evaluation of its effects on e.g. FA synthesis challenging. In this study, we found some positive 342 and some negative effects of osmotrophic assimilation on FA synthesis, but the effects were still 343 minor in general, which agrees with the study of Galloway and Winder (2015), who reported that 344 growth conditions account for relatively low variation in algal FAs. However, in extreme 345 conditions, e.g. during enhanced run-off (either due to climate change or seasonality) leading to 
346 higher carbon or amino acids in the water, the magnitude of the effects on LC-PUFA availability

347 could be significant at food web level (from algae to fish; Jonasdottir 1994; Brett et al. 2006;

348 Peltomaa et al. 2017; Taipale et al. 2018) assuming that the LC-PUFA producers of the algal

349 community would consist of species capable on osmotrophic uptake of these compounds.

350

\section{Conclusions}

352 Our experiments show that osmotrophic nutrition can be found in different types of algae, but the

353

354

355

356

357

358

359

360

361

362

363

364

365

366

367

368

369 assimilation is species specific and may differ between different organic compounds, as shown here with glucose and leucine. Furthermore, the effects of these two compounds on the algal growth and metabolism was found to be species specific: moderate glucose concentration (2 mg $\mathrm{L}^{-1}$ ) enhanced the growth of $C$. ozolinii, whereas the growth of M. kalinae was enhanced by low leucine $\left(20 \mu \mathrm{g} \mathrm{L}^{-1}\right)$. Additionally, high glucose content $\left(5 \mathrm{mg} \mathrm{L}^{-1}\right)$ affected negatively on the total fatty acids of M. kalinae and the total omega-3 fatty acids of Cryptomonas sp. In general, glucose assimilation explained 35\% (negative effect) and leucine assimilation 48\% (positive effect) of the variation of EPA, DHA and the fatty acids related to their synthesis in Cryptomonas sp. but not in the other algae studied. The broad spectrum of compounds and the species-specific responses of algae makes the estimation of the importance of osmotrophy challenging in planktonic food webs and natural waters in general.

\section{Acknowledgements}

The authors would like to thank the reviewers for all of their careful, constructive and insightful comments in relation to this work, Miss Paula Ilut for helping with the algal culturing and Mr. Roy Nyberg for editing the English of this manuscript. 


\section{References}

371 Beamud, S.G., Karrasch, B., Pedrozo, F.L., Diaz, M.M. Utilisation of organic compounds by

372 osmotrophic algae in an acidic lake of Patagonia (Argentina). Limnology 15 (2014) 163-172, 373 doi: 10.1007/s10201-014-0427-2.

374 Boechat, I.G., Weithoff, G., Kruger, A. Gucker, B., Adrian, R. A biochemical explanation for the

375 success of mixotrophy in the flagellate Ochromonas sp. Limnol. Oceanogr. 52 (2007) 16243761632.

377 Boelen, P., van Mastrigt, A., van de Bovenkamp, H.H., Heeres, H,J., Buma, A.G.J. Growth 378 phase significantly decreases the DHA-to-EPA ratio in marine microalgae. Aquacult Int 25 379 (2017) 577, https://doi.org/10.1007/s10499-016-0053-6

380 Brek-Laitinen, G., López Bellido, J., Ojala, A. Response of a microbial food web to prolonged 381 seasonal hypoxia in a boreal lake. Aquat Biol 14 (2012) 105-120.

382 Brennan, P.J. Mycobacterium and other actinomycetes. In: Microbial Lipids, Vol. 1 (Eds C.

383 Ratledge \& S.G. Wilkinson), 1989 pp. 203-298. Academic Press, London.

384 Brett, M.T., Müller-Navarra, D.C., Ballantyne, A.P., Ravet, J.L., Goldman, C.R. Daphnia fatty 385 acid composition reflects that of their diet. Limnol.Oceanogr. 51 (2006) 2428-2437.

386 Cavalier-Smith, T. Kingdoms protozoa and chromista and the eozoan root of the eukaryotic tree. 387 Biol. Lett. 6 (2010) 342-345.

388 Colombo, S.M., Wacker, A., Parrish, C.C., Kainz, M.J., Arts, M.T. A fundamental dichotomy in 389 long-chain polyunsaturated fatty acid abundance between and within marine and terrestrial 390 ecosystems. Environ. Rev. 25 (2017) 163-174.

391 Dąbrowska, A., Nawrocki, J., Szeląg-Wasielewska, E. Appearance of aldehydes in the surface 392 layer of lake waters. Environ Monit Assess 186 (2014) 4569-4580, doi 10.1007/s10661-014393 3720-y.

394 Flynn, K.J., Stoecker, D.K., Mitra, A., Raven, J.A., Glibert, P.M., Hansen, P.J., Granéli, E., 395 Burkholder, J.M. Misuse of the phytoplankton - zooplankton dichotomy: the need to assign 396 organisms as mixotrophs within plankton functional types. J. Plankton Res. 35 (2013) 3-11. 397 doi:10.1093/plankt/fbs062.

398 Galloway, A.W.E., Winder, M. Partitioning the relative importance of phylogeny and 399 environmental condition on phytoplenkton fatty acids. Plos One, 10 (2015) e0130053, 400 doi:10.1371/journal.pone.0130053. 
401 Guillard, R.R.L., Lorenzen, C.J. Yellow-green algae with chlorophyllide C. J. Phycol. 8 (1972) 402 10-14.

403 Hellebust, J.A. Excretion of some organic compounds by marine phytoplankton. Limnol

404 Oceanogr 10 (1965) 192-206.

405 Jonasdottir, S.H. Effects of food quality on the reproductive success of Acartia tonsa and Acartia 406 hudsonica-laboratory observations. Mar. Biol. 121 (1994) 67-81.

407 Kamjunke, N., Tittel, J. Utilisation of leucine by several phytoplankton species. Limnologica 38 408 (2008) 360-366.

409 Kamjunke, N., Köhler, B., Wannicke, N., Tittel, J. Algae as competitors for glucose with 410 heterotrophic bacteria. J Phycol. (2008) 616-23. doi:10.1111/j.1529-8817.2008.00520.x.

411 Kohli, G.S., John, U., Van Dolah, F.M., Murray, S.A. Evolutionary distinctiveness of fatty acid 412 and polyketide synthesis in eukaryotes. Isme Journal 10 (2016) 1877-1890.

413 Liang, Y., Sarkany, N., Cui, Y. Biomass and lipid productivities of Chlorella vulgaris under 414 autotrophic, heterotrophic and mixotrophic growth conditions. Biotechnol Lett 31 (2009) 1043415 1049, doi:10.1007/s10529-009-9975-7.

416 Mühlroth, A., Li, K., Røkke, G., Winge, P., Olsen, Y., Hohmann-Marriott, M.F., Vadstein, O., 417 Bones, A.M. Pathways of Lipid Metabolism in Marine Algae, Co-Expression Network,

418 Bottlenecks and Candidate Genes for Enhanced Production of EPA and DHA in Species of 419 Chromista. Mar. Drugs 11 (2013) 4662-4697; doi:10.3390/md11114662.

420 Norrman, B., Zwelfel, U.L., Hopkinson, C.S., Fry, B. Production and utilization of dissolved 421 organic carbon during an experimental diatom bloom. Limnol Oceanogr 40 (1995) 898-907. 422 North, B.B., Stephens, G.C. Amino acid transport in Nitzschia ovalis Arnott. J. Phycol., 8 (1972) 423 64-68.

424 Ojala, A., López Bellido, J., Tulonen, T., Kankaala, P., Huotari, J. Carbon gas fluxes from a 425 brown-water and a clear-water lake in the boreal zone during a summer with extreme rain events. 426 Limnol Oceanogr 56 (2011) 61-76.

427 Parrish, C.C. Determination of total lipid, lipid classes, and fatty acids in aquatic samples in M.T. 428 Arts and B.C. Wainman (Eds.) Lipids in Freshwater Ecosystems, Springer-Verlag, 1999, pp 442920. 
430 Peltomaa, E.T., Aalto, S.L., Vuorio, K.M., Taipale, S.J. The Importance of Phytoplankton

431 Biomolecule Availability for Secondary Production. Front. Ecol. Evol. (2017) 5:128. doi:

$43210.3389 /$ fevo.2017.00128.

433 Peltomaa, E., Ojala, A. Size-related photosynthesis of algae in a strongly stratified humic lake. J

434 Plankton Res 32 (2010) 341-355.

435 Ratledge, C. Fatty acid biosynthesis in microorganisms being used for Single Cell Oil

436 production. Biochimie 86 (2004) 807-815. doi:10.1016/j.biochi.2004.09.017

437 Rengefors, K., Pålsson, C., Hansson, L.A., Heiberg, L. Cell lysis of competitors and osmotrophy 438 enhance growth of the bloom-forming alga Gonyostomum semen. Aquat Microb Ecol 51 (2008)

439 87-96. doi:10.3354/ame01176.

440 Roessler, P.G. Environmental control of glycerolipid metabolism in microalgae: commercial

441 implications and future research directions. J Phycol 26 (1990) 393-399.

442 Ruiz-González, C., Galí, M., Sintes, E., Herndl, G.J., Gasol, J.M., Simó, R. Sunlight Effects on

443 the Osmotrophic Uptake of DMSP-Sulfur and Leucine by Polar Phytoplankton. PLoS ONE 7(9)

444 (2012) e45545. doi:10.1371/journal.pone.0045545.

445 Schmidt, S., Raven, J.A., Paungfoo-Lonhienne, C. The mixotrophic nature of photosynthetic

446 plants. Funct. Plant Biol. 40 (2013) 425-438.

447 Taipale, S.J., Kahilainen, K.K., Holtgrieve, G.V., Peltomaa, E.T. Simulated eutrophication and

448 browning alters zooplankton nutritional quality and determines juvenile fish growth and survival.

449 Ecol Evol 8 (2018) 2671-2687, doi.org/10.1002/ece3.3832.

450 Taipale, S.J., Hiltunen, M., Vuorio, K., Peltomaa, E. Suitability of phytosterols alongside fatty

451 acids as chemotaxonomic biomarkers for phytoplankton. Front Plant Sci 7 (2016) 212. doi:

$45210.3389 /$ fpls.2016.00212.

453 Taipale, S.J., Peltomaa, E., Hiltunen, M., Jones, R.I., Hahn, M.W., Biasi, C., Brett, M.T.

454 Inferring phytoplankton, terrestrial plant and bacteria bulk $\delta^{13} \mathrm{C}$ values from compound specific

455 analyses of lipids and fatty acids. PLoS ONE 10 (2015) e0133974,

456 doi:10.1371/journal.pone.0133974

457 Taipale S., Kankaala, P., Tiirola, M., Jones, R.I. Whole-lake DI13C additions reveal seasonal

458 shifts between multiple food source contributions to zooplankton diet. Ecology 89 (2008) 463 459474. 
460 Tittel, J., Wiehle, I., Wannicke, N., Kampe, H., Poerschmann, J., Meier, J., Kamjunke, N.

461 Utilisation of terrestrial carbon by osmotrophic algae. Aquat Sci 71 (2009) 46-54.

462 Wan, M., Liu, P., Xia, J., Rosenberg, J.N., Oyler, G.A., Betenbaugh, M.J., Nie, Z., Qiu, G. The

463 effect of mixotrophy on microalgal growth, lipid content, and expression levels of three pathway

464 genes in Chlorella sorokiniana. Appl Microbiol Biotechnol 91 (2011) 835-844,

465 doi:10.1007/s00253-011-3399-8.

466 Watanabe, M.M., Kawachi, M., Hiroki, M., Kasai, F. (Eds.) NIES Collection List of Strains. 6th 467 Ed., 2000, 159 pp.

468 Wheeler, P.A., North, B.B., Stephens, G.C. Amino acid uptake by marine phytoplankters.

469 Limnol Oceanogr 19 (1974) 249-259.

470 Willén, T. Studies on the phytoplankton of some lakes connected with or recently isolated from

471 the Baltic. Oikos 13 (162) 169-199.Yoo, Y.D., Seong, K.A., Jeong, H.J., Yih, W., Rho, J.R.,

472 Nam, S.W., Kim, H.S. Mixotrophy in the marine red-tide cryptophyte Teleaulax amphioxeia and

473 ingestion and grazing impact of cryptophytes on natural populations of bacteria in Korean

474 coastal waters. Harmful Algae 68 (2017) 105-117, doi:10.1016/j.hal.2017.07.012 


\section{Table $\mathbf{1}$ (on next page)}

Growth rates

Table 1. The maximal specific growth rates $\left(\mu ; \mathrm{d}^{-1}\right)$ of Mallomonas kalinae, Cryptomonas sp. and $C$. ozolinii in the long-term experiment. The growth rates were calculated for the exponential growth phase using equation 1. Replication $n=3, * A N O V A p<0.01$, standard deviations are given in parenthesis. 
1 Table 1. The maximal specific growth rates $\left(\mu ; \mathrm{d}^{-1}\right)$ of Mallomonas kalinae, Cryptomonas sp.

2 and C. ozolinii in the long-term experiment. The growth rates were calculated for the exponential

3 growth phase using equation 1 . Replication $n=3$, *ANOVA $p<0.01$, standard deviations are

4 given in parenthesis.

5

Strain

Mallomonas kalinae

Cryptomonas sp.

Cryptomonas ozolinii

\section{Control}

$0.20(0.03)$

$0.21(0.04)$

$0.52(0.01)$
Glucose 0.5

$0.20(0.08)$

$0.23(0.06)$

$0.41(0.01)$

\section{Glucose 2 Glucose 5}

$0.23(0.01) \quad 0.20(0.01)$ $0.36(0.05) \quad 0.26(0.02)$

$0.88(0.07)^{*}$
$0.47(0.05)^{*}$

$0.23(0.04)$

$0.34(0.05)$
$0.20(0.04)$

$0.25(0.05)$

0.65 (0.05)
$0.16(0.06)$

$0.28(0.03)$

$0.57(0.02)$

6 


\section{Table 2 (on next page)}

Fatty acid results

Table 2. The concentrations ( $\mu \mathrm{g}$ in mg dry weight) of $16: 0$ fatty acid (FA), alpha-linolenic

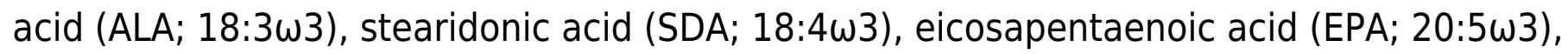
docosahexaenoic acid (DHA; 22:6w3), total omega-3 ( $\omega-3)$ FAs and total FAs in M. kalinae, Cryptomonas sp. and C. ozolinii in autotrophic controls and when grown osmotrophically with different glucose (i.e. $\left.0.5 \mathrm{mg} \mathrm{L}^{-1}, 2 \mathrm{mg} \mathrm{L}^{-1}, 5 \mathrm{mg} \mathrm{L}^{-1}\right)$ and leucine $\left(20 \mathrm{mg} \mathrm{L}^{-1}, 100 \mathrm{mg} \mathrm{L}^{-1}, 400 \mathrm{mg}\right.$ $\mathrm{L}^{-1}$ ) concentrations in the long-term experiment. Replication $n=3$. Standard deviations are given in parenthesis. Different letters $(a, b, c)$ denote significant differences (Tukey's HSD p $<0.05)$ between treatments, only statistically significant results are indicated. 
1 Table 2. The concentrations ( $\mu \mathrm{g}$ in $\mathrm{mg}$ dry weight) of 16:0 fatty acid (FA), alpha-linolenic acid (ALA; 18:3 03 ), stearidonic acid

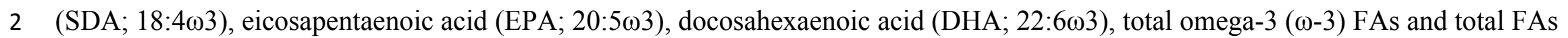

3 in M. kalinae, Cryptomonas sp. and C. ozolinii in autotrophic controls and when grown osmotrophically with different glucose (i.e. 0.5

$\left.4 \mathrm{mg} \mathrm{L}^{-1}, 2 \mathrm{mg} \mathrm{L}^{-1}, 5 \mathrm{mg} \mathrm{L}^{-1}\right)$ and leucine (20 $\left.\mathrm{mg} \mathrm{L}^{-1}, 100 \mathrm{mg} \mathrm{L}^{-1}, 400 \mathrm{mg} \mathrm{L}^{-1}\right)$ concentrations in the long-term experiment. Replication

$5 \mathrm{n}=3$. Standard deviations are given in parenthesis. Different letters (a, b, c) denote significant differences (Tukey's HSD $p<0.05)$

6 between treatments, only statistically significant results are indicated.

\begin{tabular}{|c|c|c|c|c|c|c|c|c|}
\hline Strain & $\begin{array}{l}\text { Fatty } \\
\text { acid }\end{array}$ & Control & Glucose 0.5 & Glucose 2 & Glucose 5 & Leucine 20 & Leucine 100 & Leucine 400 \\
\hline \multicolumn{9}{|c|}{ Mallomonas kalinae } \\
\hline & $16: 0$ & $8.2(2.3)$ & $4.1(0.1)$ & $7.9(1.5)$ & $5.0(1.9)$ & $8.1(1.0)$ & $4.0(0.1)$ & $6.8(1.9)$ \\
\hline & ALA & $7.3(0.0)^{\mathrm{a}}$ & $6.7(4.1)^{\mathrm{ab}}$ & $8.3(0.0)^{\mathrm{b}}$ & $4.8(4.7)^{\mathrm{abc}}$ & $10.9(1.1)^{\mathrm{b}}$ & $4.6(0.3)^{c}$ & $8.0(1.1)^{\mathrm{ab}}$ \\
\hline & SDA & $10.3(1.6)^{\mathrm{a}}$ & $8.3(6.3)^{\mathrm{a}}$ & $9.0(1.4)^{\mathrm{a}}$ & $6.2(5.4)^{\mathrm{ab}}$ & $12.9(1.2)^{\mathrm{a}}$ & $5.6(0.4)^{b}$ & $10.6(3.9)^{\mathrm{ab}}$ \\
\hline & EPA & $0.3(0.0)^{a}$ & $0.2(0.1)^{\mathrm{ab}}$ & $0.3(0.0)^{\mathrm{a}}$ & $0.2(0.1)^{\mathrm{ab}}$ & $0.3(0.0)^{a}$ & $0.1(0.0)^{b}$ & $0.3(0.0)^{a}$ \\
\hline & $\mathrm{DHA}$ & $0.8(0.0)$ & $0.7(0.5)$ & $0.8(0.1)$ & $0.6(0.3)$ & $1.0(0.1)$ & $0.4(0.0)$ & $0.7(0.2)$ \\
\hline & Total FA & $88.8(5.8)^{\mathrm{a}}$ & $70.3(8.7)^{\mathrm{ab}}$ & $74.1(18.9)^{\mathrm{ab}}$ & $33.8(14.8)^{\mathrm{bc}}$ & $63.8(27.9)^{\mathrm{ab}}$ & $45.6(0.3)^{\mathrm{b}}$ & $56.8(22.3)^{\mathrm{ab}}$ \\
\hline \multicolumn{9}{|c|}{ Cryptomonas sp. } \\
\hline & $16: 0$ & $7.8(1.0)^{\mathrm{ab}}$ & $7.8(1.6)^{\mathrm{ab}}$ & $13.6(0.4)^{b}$ & $8.6(0.7)^{a b}$ & $10.4(1.2)^{\mathrm{ab}}$ & $7.6(2.0)^{\mathrm{ab}}$ & $10.2(0.3)^{a}$ \\
\hline & ALA & $21.7(3.7)^{\mathrm{ab}}$ & $16.8(2.3)^{\mathrm{ab}}$ & $23.2(0.3)^{\mathrm{a}}$ & $18.9(3.2)^{\mathrm{ab}}$ & $20.1(0.9)^{\mathrm{ab}}$ & $17.1(1.2)^{\mathrm{ab}}$ & $18.0(0.2)^{b}$ \\
\hline & SDA & $11.5(2.2)$ & $14.9(1.3)$ & $17.1(2.6)$ & $15.1(3.8)$ & $20.8(2.2)$ & $13.3(4.0)$ & $23.0(1.2)$ \\
\hline & EPA & $13.1(2.1)^{\mathrm{a}}$ & $11.5(0.5)^{\mathrm{ab}}$ & $13.6(3.3)^{\mathrm{ab}}$ & $12.3(2.7)^{\mathrm{ab}}$ & $14.9(2.5)^{\mathrm{ab}}$ & $11.1(3.0)^{\mathrm{ab}}$ & $16.8(0.4)^{b}$ \\
\hline & DHA & $1.4(0.0)$ & $2.0(0.2)$ & $2.1(0.6)$ & $1.8(0.6)$ & $2.8(0.3)$ & $1.7(0.6)$ & $3.4(0.2)$ \\
\hline
\end{tabular}




$\begin{array}{lccccccc}\text { Total FA } & 60.7(2.1) & 52.8(16.5) & 73.6(3.1) & 70.5(15.6) & 67.7(16.2) & 55.9(7.8) & 68.8(26.1) \\ & & & & & & \\ & & & & & & & \\ \text { 16:0 } & 4.3(0.0) & 5.2(1.5) & 4.8(1.5) & 4.6(0.2) & 5.3(1.0) & 4.5(0.2) & 5.0(0.1) \\ \text { ALA } & 8.1(1.3) & 10.1(3.6) & 9.5(4.1) & 9.0(0.8) & 10.9(2.1) & 9.2(0.5) & 8.5(2.8) \\ \text { SDA } & 8.5(0.2) & 11.7(4.2) & 10.9(6.1) & 11.1(0.8) & 13.6(1.7) & 11.5(1.2) & 10.0(3.7) \\ \text { EPA } & 7.0(2.6)^{\mathrm{a}} & 8.9(2.8)^{\mathrm{ab}} & 8.5(4.5)^{\mathrm{ab}} & 9.1(1.8)^{\mathrm{ab}} & 11.1(0.1)^{\mathrm{b}} & 9.7(1.6)^{\mathrm{ab}} & 8.2(2.5)^{\mathrm{ab}} \\ \text { DHA } & 1.6(0.0)^{\mathrm{a}} & 2.2(0.7)^{\mathrm{ab}} & 2.0(1.2)^{\mathrm{ab}} & 2.4(0.7)^{\mathrm{ab}} & 2.8(0.0)^{\mathrm{b}} & 2.6(0.5)^{\mathrm{ab}} & 2.0(0.7)^{\mathrm{ab}} \\ \text { Total FA } & 35.9(7.1) & 35.2(0.3) & 44.8(18.0) & 37.1(4.6) & 45.1(16.9) & 43.0(9.6) & 32.9(2.8)\end{array}$




\section{Table 3 (on next page)}

PERMANOVA results

Table 3. Permutational multivariate analysis of variances (PERMANOVA) results for comparisons of the similarity of the concentrations of selected FAs (16:0, ALA, SDA, EPA, DHA, 16 MUFA, 18 MUFA) between the treatments in the long-term experiment. For the analysis, all glucose and all leucine treatments were pooled, thus replication $n=9$. SS sum of squares, MS, mean squares, $\mathrm{P}($ perm) significance, $\mathrm{P}(\mathrm{MC})$ significance after Montecarlo correction. Statistically significant results are bolded. 
1 Table 3. Permutational multivariate analysis of variances (PERMANOVA) results for

2 comparisons of the similarity of the concentrations of selected FAs (16:0, ALA, SDA, EPA,

3 DHA, 16 MUFA, 18 MUFA) between the treatments in the long-term experiment. For the

4 analysis, all glucose and all leucine treatments were pooled, thus replication $\mathrm{n}=9$. SS sum of

5 squares, MS, mean squares, $\mathrm{P}($ perm) significance, $\mathrm{P}(\mathrm{MC})$ significance after Montecarlo

6 correction. Statistically significant results are bolded.

7

$\begin{array}{lllrrrrr}\text { Strain } & \text { Treatment } & \text { df } & \text { SS } & \text { MS } & \text { Pseudo-F } & \text { P(perm) } & \text { P(MC) } \\ \text { Mallomonas kalinae } & \begin{array}{l}\text { glucose } \\ \text { leucine }\end{array} & 3 & 1697.1 & 565.71 & 1.4768 & 0.253 & 0.271 \\ & & & 1564.9 & 521.63 & 1.3617 & 0.331 & 0.339 \\ \text { Cryptomonas sp. } & \begin{array}{l}\text { glucose } \\ \text { leucine }\end{array} & 3 & 375.57 & 125.19 & 2.7389 & \mathbf{0 . 0 2 5} & \mathbf{0 . 0 4 7} \\ & & & 518.04 & 172.68 & 3.7779 & \mathbf{0 . 0 2 1} & \mathbf{0 . 0 3} \\ \text { Cryptomonas ozolinii } & \begin{array}{l}\text { glucose } \\ \text { leucine }\end{array} & 3 & 117.55 & 39.184 & 0.20727 & 0.918 & 0.898 \\ & 3 & 339.31 & 113.1 & 0.59828 & 0.702 & 0.654\end{array}$




\section{Figure 1}

Osmotrophic glucose and leucine assimilation

Figure 1. The osmotrophic glucose and leucine assimilation in the studied algal strains was detected with stable isotope labelling. The figures show the isotopic difference in ${ }^{13} \mathrm{C}$ (panel A) and ${ }^{15} \mathrm{~N}$ (panel B) between the treatments in Cryptomonas sp., Cryptomonas ozolinii, Chlamydomonas reinhardtii, Euglena gracilis, Mallomonas kalinae, Peridinium sp. and Selenastrum sp. in the short-term experiment. The cultures were inoculated with ${ }^{13} \mathrm{C}$-labeled glucose, ${ }^{15} \mathrm{~N}$-labeled leucine and mixture of these two. The total concentration of glucose in the experiment was $5 \mathrm{mg} \mathrm{L}^{-1}$ and leucine $400 \mathrm{mg} \mathrm{L}^{-1}$. Replication $\mathrm{n}=3$. The bars show standard errors, statistically significant difference between the non-labeled and labeled treatments are marked with star symbols (ANOVA, $* p<0.5$, ** $p<0.1$ and $* * * p<0.01$ ). 


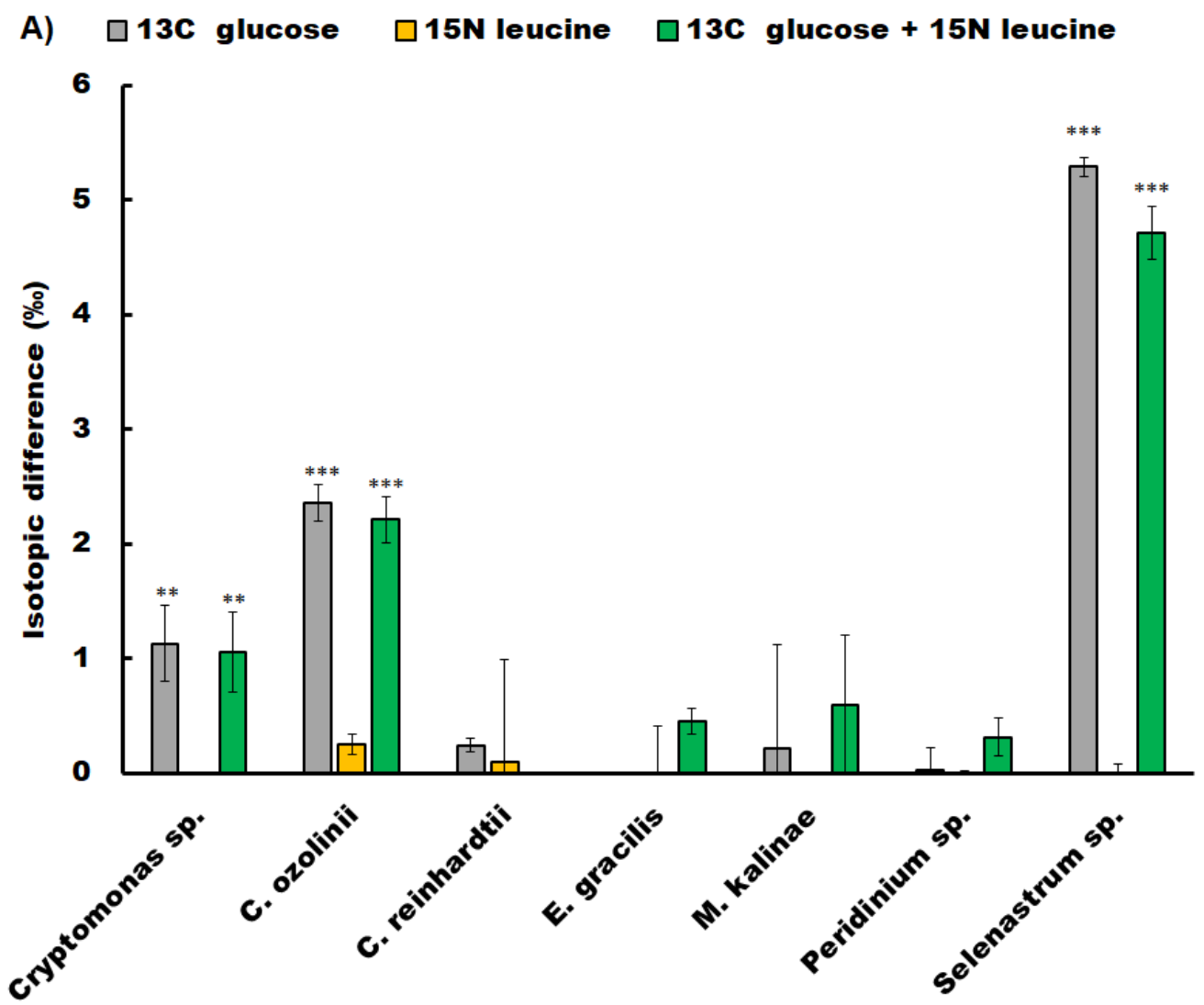

B) $\square 13 \mathrm{C}$ glucose $\square 15 \mathrm{~N}$ leucine $\square 13 \mathrm{C}$ glucose $+15 \mathrm{~N}$ leucine

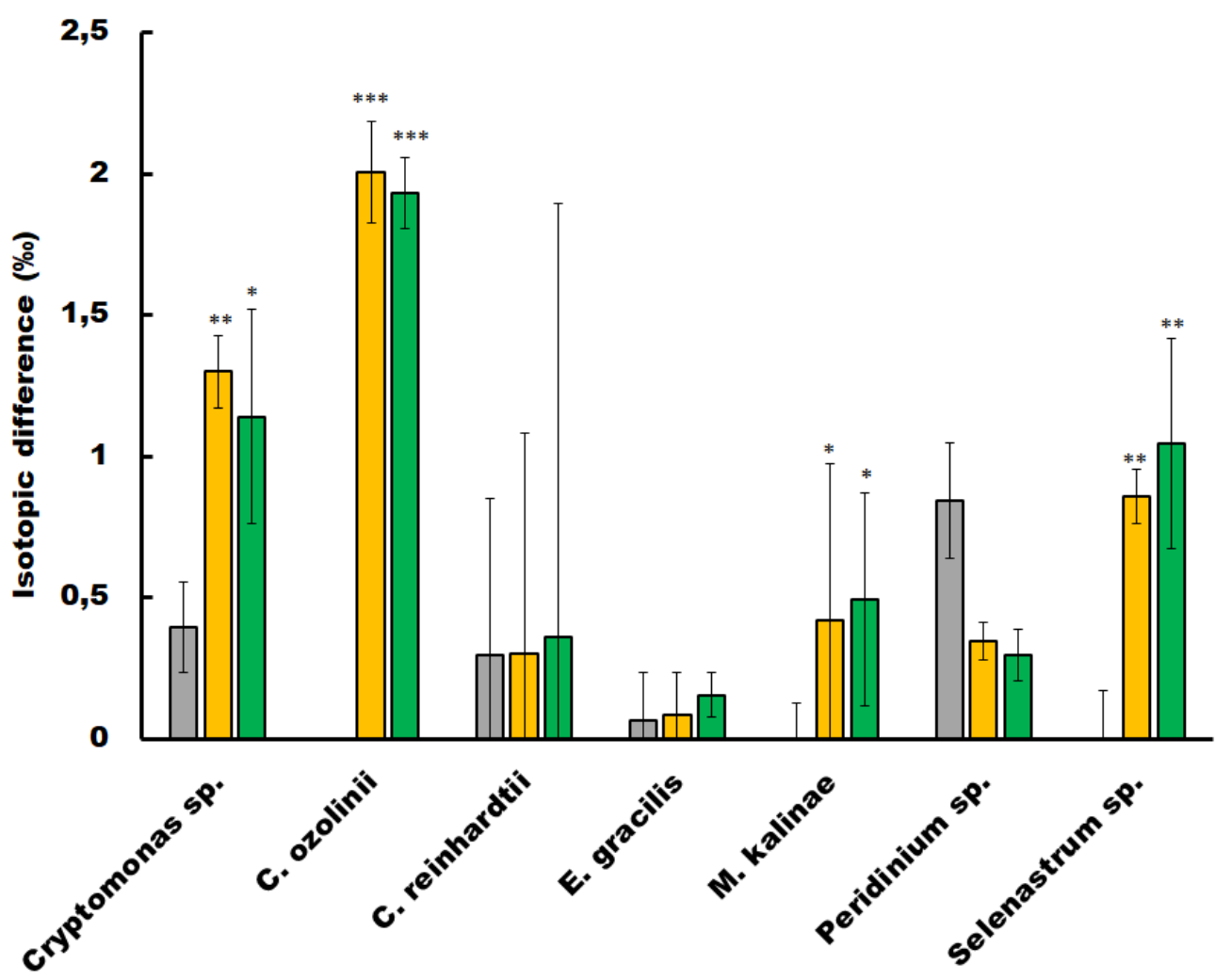


Figure 2

Fatty acid contents

Figure 2. The proportions of omega-3 FAs (alpha-linolenic acid, ALA; 18:3w3, stearidonic

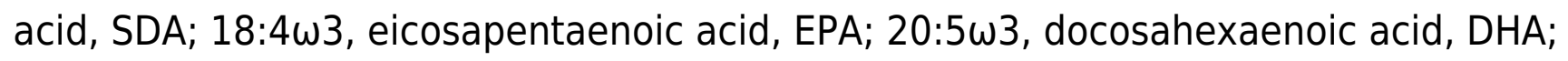
22:6w3) on total omega-3 FAs in (A) M. kalinae, (B) Cryptomonas sp. and (C) C. ozolinii in autotrophic controls and when grown osmotrophically with different glucose (i.e. $0.5 \mathrm{mg} \mathrm{L}^{-1}, 2$ $\mathrm{mg} \mathrm{L}^{-1}, 5 \mathrm{mg} \mathrm{L}^{-1}$ ) and leucine ( $\left.20 \mathrm{mg} \mathrm{L}^{-1}, 100 \mathrm{mg} \mathrm{L}^{-1}, 400 \mathrm{mg} \mathrm{L}^{-1}\right)$ concentrations in the longterm experiment. Replication $n=3$. 
A)

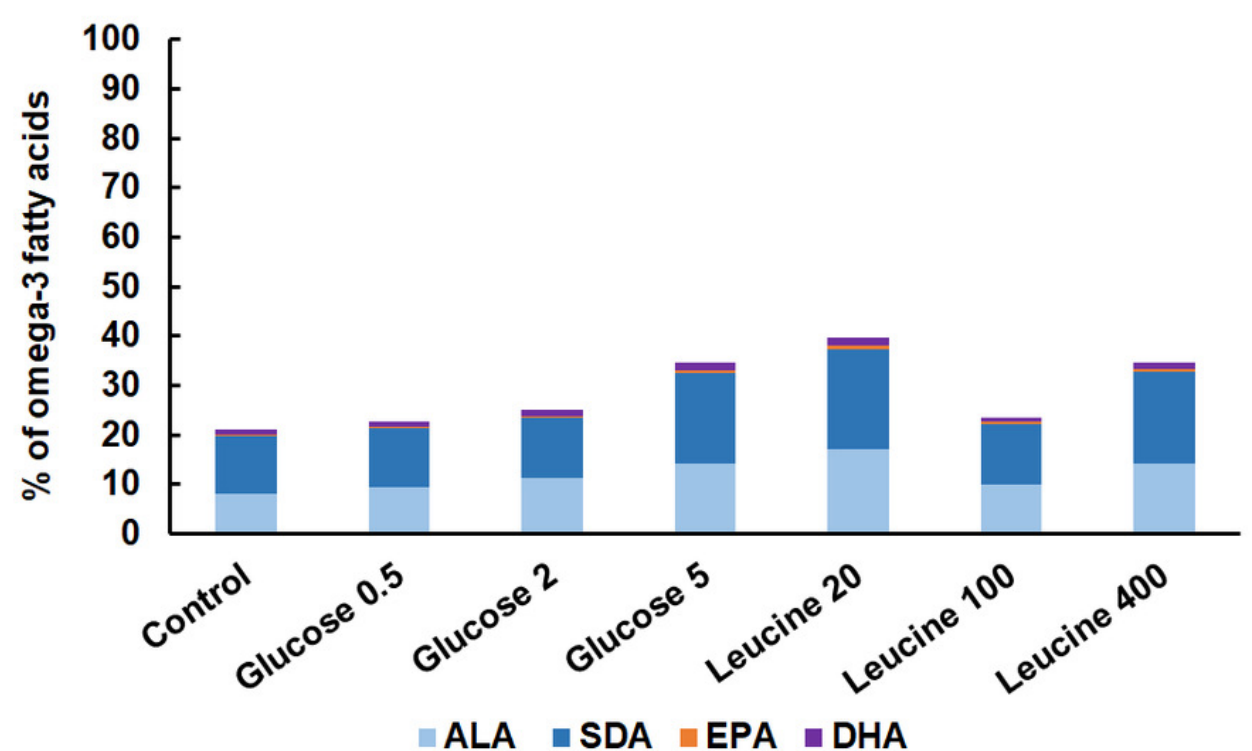

B)

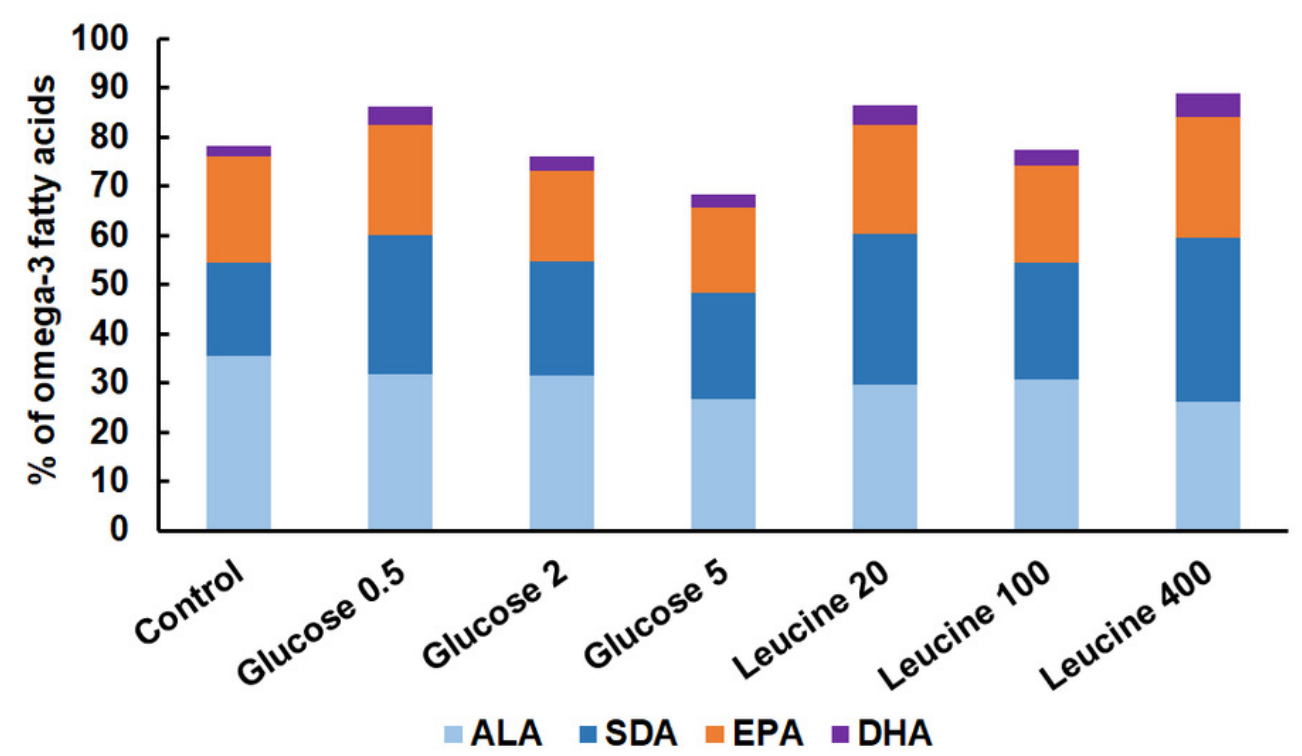

C)

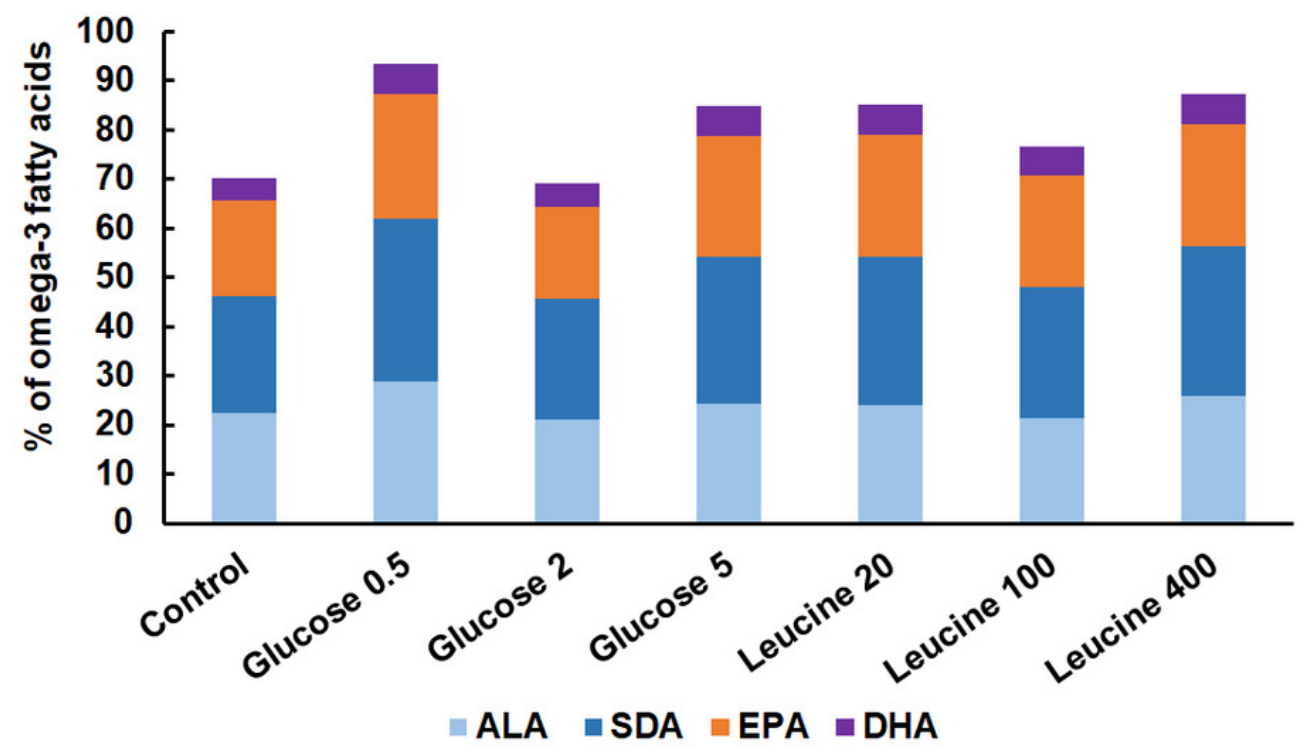


Figure 3

PCA plot

Figure 3. Principal component analysis (PCA) plot of the 16:0 fatty acid (FA), alpha-linolenic

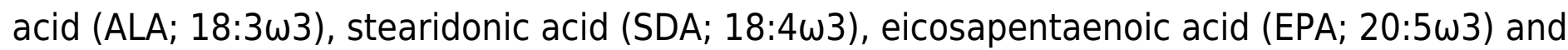
docosahexaenoic acid (DHA; 22:6w3) of the long-term experiment showing that the studied three strains (Mallomonas kalinae, Cryptomonas sp. (CPCC 336) and C. ozolinii) differ from each other based on these FAs despite of the growth conditions (autotrophic, or osmotrophic with glucose or leucine; data shown in Table S2).

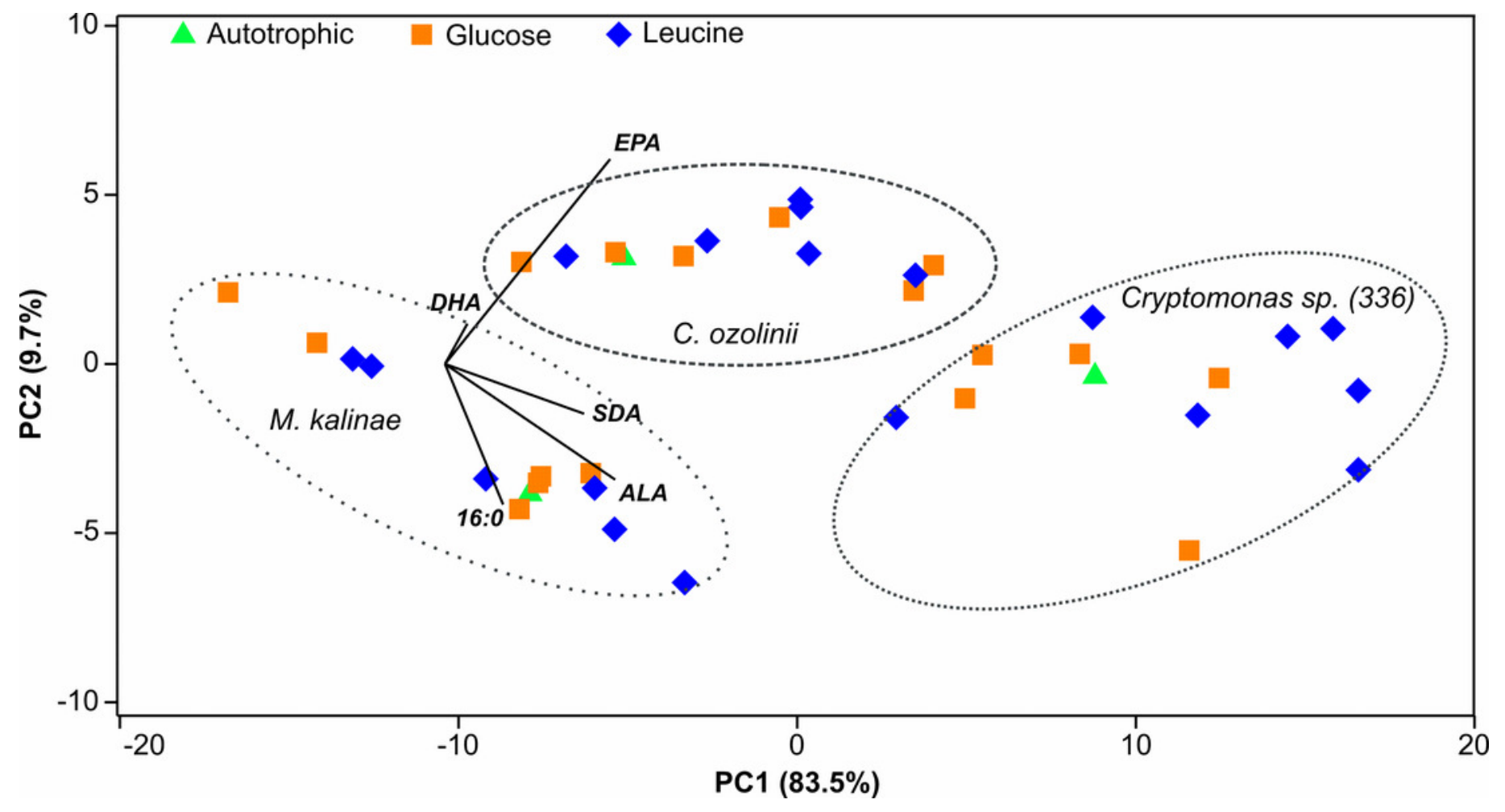

